\title{
Comparative Study of 3D Simulation and Experiment on Stator MPPUA of Generator under FWISC Faults with Different Degrees
}

\author{
Yu-Ling He ${ }^{1}$, Qing-Fa Meng ${ }^{1}$, Ping Wang ${ }^{2}$, Ming-Xing Xu ${ }^{1}$ \\ ${ }^{1}$ North China Electro Power University \\ ${ }^{1}$ North China Electric Power University \\ ${ }^{2}$ Harbin University of Science and Technology Rongcheng Campus \\ ${ }^{1}$ North China Electric Power University
}

\begin{abstract}
In order to study the impacts of the stator magnetic pull per unit area (MPPUA) characteristics under different field winding inter-turn short-circuit (FWISC) degrees in generator, comparative study of 3D numerical simulations and experiments are respectively taken to calculate the quantitative data of stator MPPUA by finite-element method (FEM) in this paper. Firstly, the nature exciting force of stator vibration, which is called MPPUA, is carried out. Then simulations data on MPPUA under normal condition and different short-circuit degrees are obtained. Finally, the variation rules of MPPUA characteristics by experiments under different conditions are studied. The results show that in normal condition the main harmonic components of MPPUA consist of only 6th-harmonic component. However, the occurrence of FWISC will bring in extra 1st, 2nd, 3rd, 4th and 5th-harmonic components to MPPUA. Meanwhile, with the increasing of the rotor short circuit degrees, the amplitudes of 1st, 2nd, 3rd, 4th and 5th-harmonic components will present an increasing trend. However, the amplitudes of 6th-harmonic component will present a decrease trend.
\end{abstract}

Keywords:Magnetic pull per unit area (MPPUA); field winding inter-turn short-circuit (FWISC); different short-circuit degrees; finite-element method (FEM)

\section{Introduction}

FWISC is a common electrical fault. When FWISC develops seriously, intensive consequences such as field current increment, reactive power output decrease, and generator-set vibration aggravation, etc., will be caused ${ }^{[1]}$. Due to the connection between the stator and the foundation, the stability of stator is relatively strong. However, Stator windings are embedded in the stator slots. Stator vibration will cause the vibration of the stator windings, which will lead to aggravate the insulation wears of the windings ${ }^{[2]}$. Therefore, it is important to study the mechanical properties on stator and find the mechanical origin of stator vibration.

So far, a lot of research work about FWISC has been carried out. Typically, the detection coil method was proposed to detect FWISC, which can judge whether there is a rotor winding inter-turn short-circuit fault, and show the location of the faulty slot by analyzing the distortion degrees of the induced potential waveform on the detection coil ${ }^{[3]}$. The formulas of the magneto motive force (MMF) and MFD are analyzed under normal condition and fault. The rules are revealed that FWISC mainly affects MMF but has a very little impact on the permeance per unit area (PPUA) ${ }^{[4]}$. In addition, the harmonic components of the parallel branch circuit on stator windings and air gap differential coil induction potential are analyzed ${ }^{[5]}$. FWISC will cause the excitation current to increase, but the reactive power is relatively reduced or unchanged, and a method to identify the rotor winding fault is found by using the relative change rate of the excitation current before and after fault. Thus a criterion for on-line identification of FWISC is established ${ }^{[6]}$. 
Currently, for the vibration characteristics of stator under FWISC, the method of stator vibration characteristic identification among single and composite faults composed of faults air-gap eccentricity and rotor inter-turn short-circuit is revealed ${ }^{[7]}$. The stator will induce the vibration at $\mathrm{f}, 2 \mathrm{f}, 3 \mathrm{f}$, and $4 \mathrm{f}$ under FWISC $^{[8]}$. The vibration characteristics of stator under compound fault are studied. And the variation rules of vibration characteristics under different fault degrees are analyzed by experiment ${ }^{[9]}$. Therefore, comparably, the influence of stator vibration on the normal operation of generator is also very huge, though most scholars have paid their primary attention to the rotor vibrations but not the stator vibration characteristics ${ }^{[10]}$. The above references could lay a solid foundation for the study of this paper.

As an improvement, for the generator $(\mathrm{p}=3)$, previous studies often use 2D models for simulation, while the simulation environment of 3D models is closer to the real operation of generator. Therefore, theoretical derivation based on $\operatorname{Ref}^{[11]}$, this paper investigates the impacts of stator MPPUA characteristics under different FWISC degrees in generator by comparative study of 3D simulation and experiment. The results in this paper are an argument and supplement to the existing technology.

\section{Exciting characteristics of MPPUA}

Generator stator is made up of the stator core, the windings, the frame, the end covers, etc. Stator vibrations are primarily produced by the magnetic forces acting on the stator core. This kind of magnetic force is actually a unit magnetic pull performing on the whole inner surface of the stator core, and usually called magnetic pull per unit area

(MPPUA), as shown in Figure 1.

MPPUA mainly acts on the stator core surface, and the composite magnetic pulls can be obtained by integrating MPPUA. Because the stator core is a shell structure that made up of silicon steel sheets, the radial rigidity is small and the composite magnetic pull is zero (shown in Figure.1 (a) and (c)). However, under the periodic MPPUA, the stator core also can generate the radial vibration, such as the periodic expansion contraction. Therefore, MPPUA is the nature exciting force of stator vibration.

Therefore, due to the specific structure of the stator core, the essential exciting force for the stator vibration is MPPUA, which can be deduced based on Eq. (1) and Eq. (2).

$$
\begin{gathered}
B\left(\alpha_{\mathrm{m}}, t\right)=f\left(\alpha_{\mathrm{m}}, t\right) \Lambda\left(\alpha_{\mathrm{m}}, t\right) \\
q\left(\alpha_{m}, t\right)=\frac{B^{2}\left(\alpha_{m}, t\right)}{2 \mu_{0}}=\frac{1}{2 \mu_{0}} \Lambda^{2}\left(\alpha_{m}, t\right) f^{2}\left(\alpha_{m}, t\right)
\end{gathered}
$$
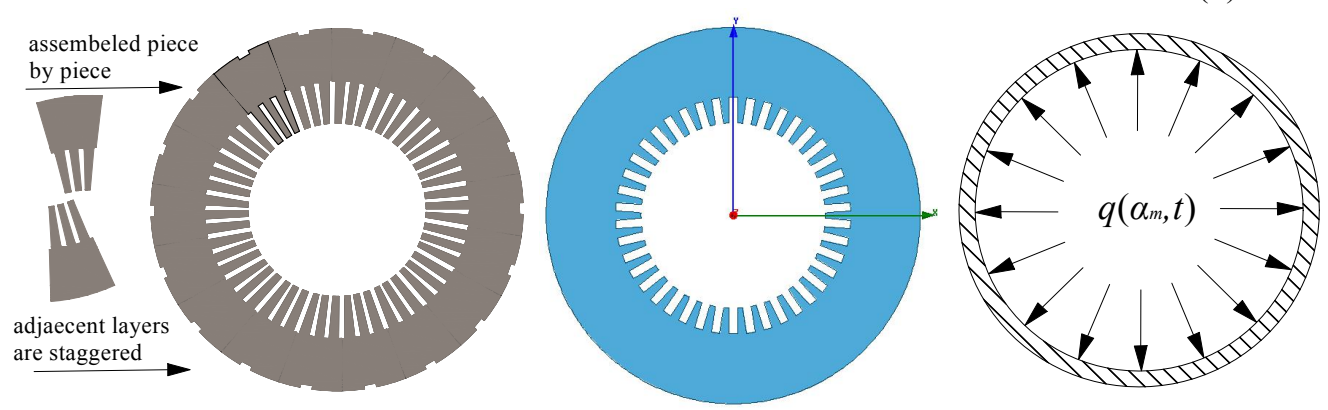
(a) Structure of stator core
(b) model of stator core
(c) MPPUA on stator core

Figure 1. Structure and magnetic force of stator core.

\section{3D numerical simulation}

\subsection{Object and method}

3D numerical simulation is taken for a MJF-30-6 type generator under normal condition and different FWISC degrees in ANSOFT. The primary parameters are indicated in Tab 1. 


\begin{tabular}{|l|l|}
\hline Parameter & Value \\
\hline Rated capacity & $30 \mathrm{KVA}$ \\
\hline Rated speed & $1000 \mathrm{rpm}$ \\
\hline Number of stator slots & 54 \\
\hline Number of rotor slots & 30 \\
\hline Number of turns in per stator slot & 72 turns \\
\hline Number of turns in per rotor slot & 88 turns \\
\hline radial length of air gap & $0.85 \mathrm{~mm}$ \\
\hline
\end{tabular}

Table 1. Primary parameters of MJF-30-6 type generator

In this paper, the excitation winding at short-circuit parts is divided into two parts: short-circuit winding and residual winding. The turns of the short-circuit winding and residual winding are equal to the turns of the original winding. When No. 2 rotor winding shorts 88 turns and No. 3 rotor winding shorts 44 turns, different short-circuit degrees can be achieved by changing No. 1 rotor winding, such as short-circuit 0 turns, 44 turns and 88 turns. In other words, different short-circuit degrees respectively are 10\%, 13.3\%, 16.7\%, as indicated in Figure 2.

Accordingly, the excitation windings in the external circuit are divided into two parts: Field_SC and Field_Leftover. Field_SC is the short-circuit winding and Field_Leftover is the residual winding. At the same time, the values of R168 and R299 are changed. R168 is the residual resistance and R299 is the short circuit resistance. R5 is the contact resistance produced by short circuit, as shown in Figure 3.
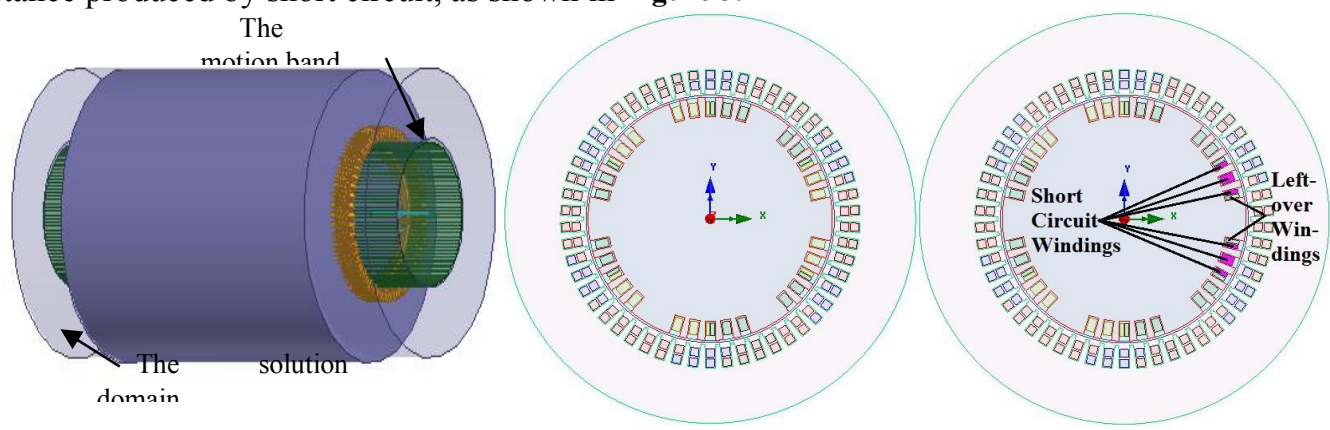
(a) 3D model
(b) Normal condition
(c) No.1 winding of FWISC

Figure 2. 3D simulation model of the generator under different conditions.

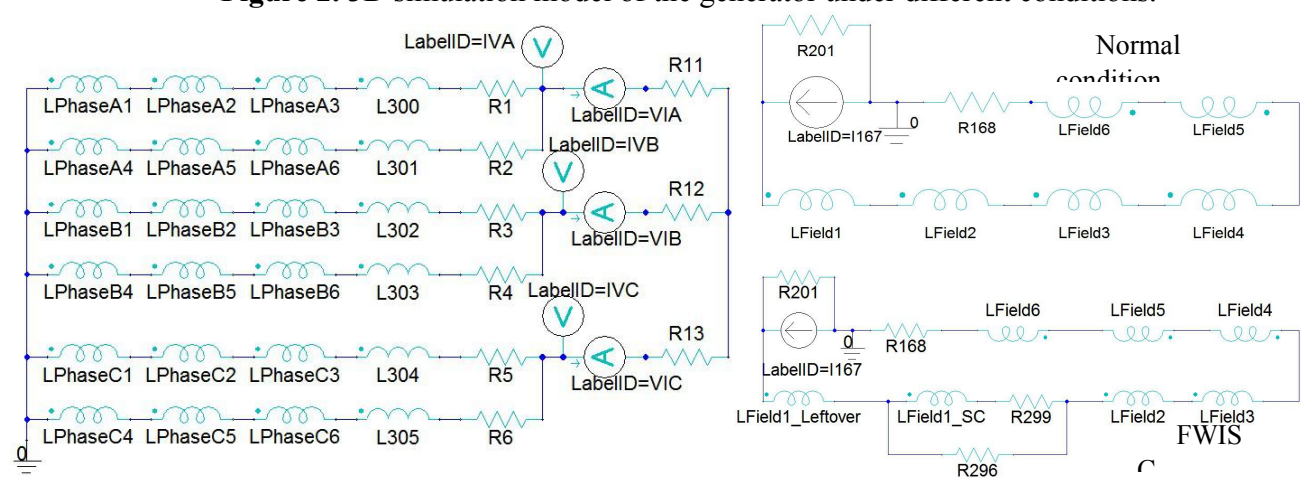

Figure 3. Coupling circuit set of the armature winding and the excitation winding.

\subsection{Results and discussion}

In order to study the variation rules of stator MPPUA, time domain waveforms of stator MPPUA as well as the spectra obtained from the 3D numerical simulation for normal condition and different short-circuit degrees are demonstrated in Figure.4. 

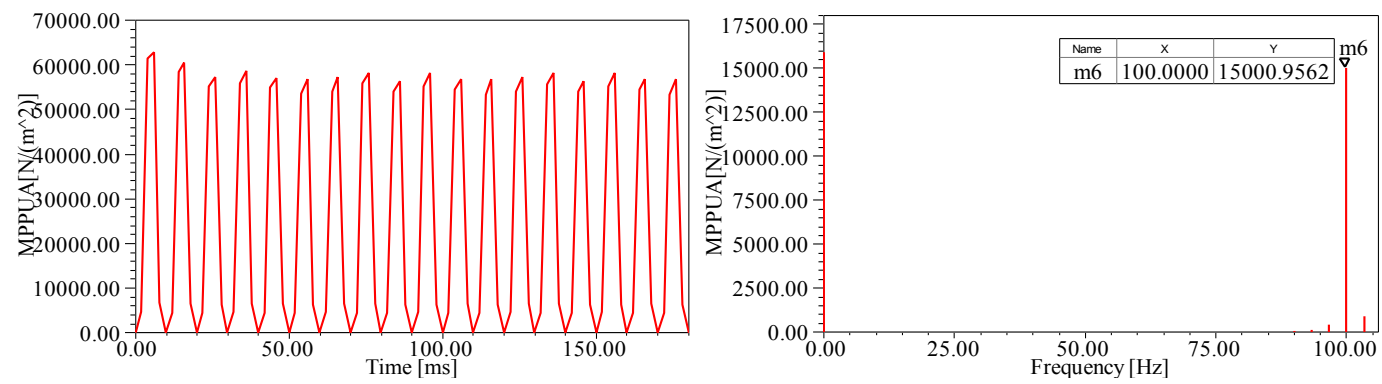

(a) Stator MPPUA waveforms and spectra under normal condition
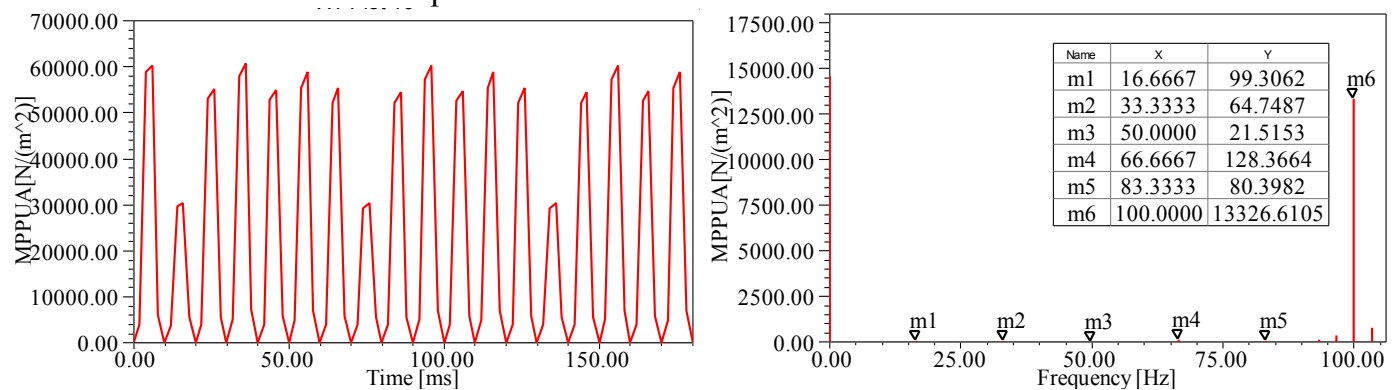

(b) Stator MPPUA waveforms and spectra under FWISC (shorted 10\%)
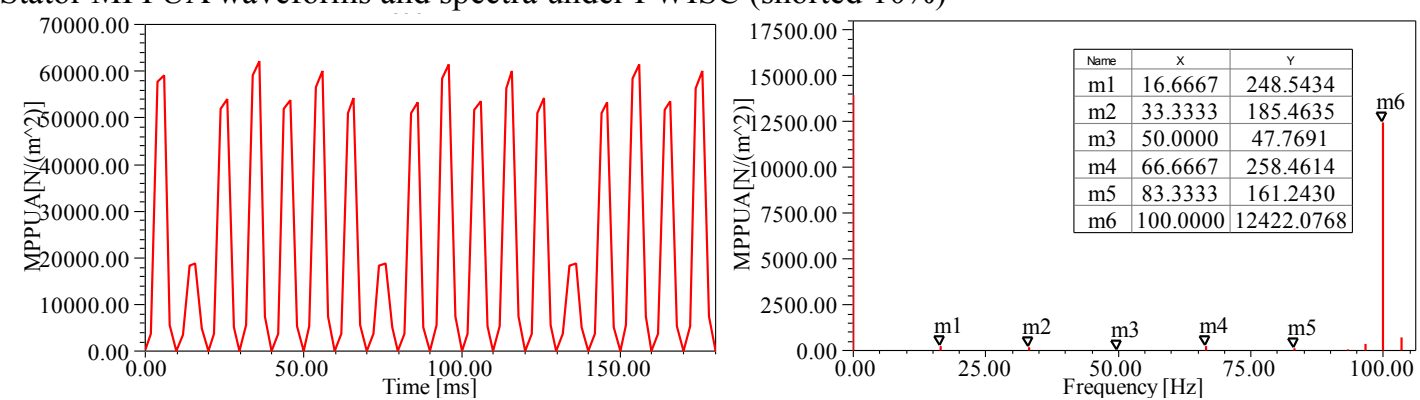

(c) Stator MPPUA waveforms and spectra under FWISC (shorted 13.3\%)
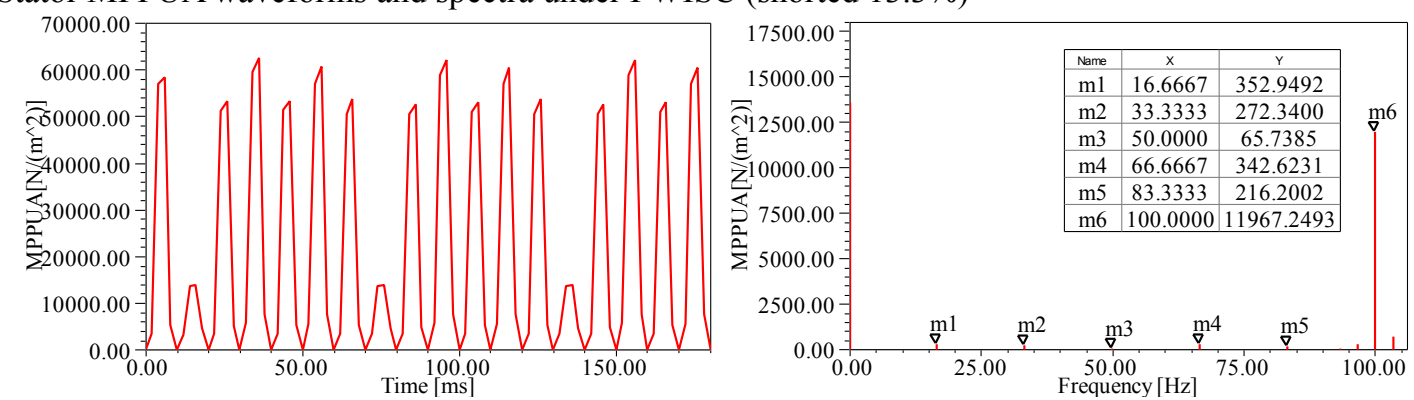

(d) Stator MPPUA waveforms and spectra under FWISC (shorted 16.7\%)

Figure 4. Stator MPPUA waveforms and spectra under different running conditions.

The main component of stator MPPUA is 6th-harmonic component under normal condition. The occurrence of FWISC will bring in 1st, 2nd, 3rd, 4th and 5th-harmonic components to MPPUA, as shown in Figure 4 (a) and (b). In other words, the main harmonic components of stator MPPUA under FWISC are 1st, 2nd, 3rd, 4th, 5th and 6th-harmonic components. Meanwhile, with the increasing of the short circuit degrees, the amplitudes of 1st, 2nd, 3rd, 4th and 5th-harmonic components will present an increasing trend. However, the amplitudes of 6th-harmonic component will present a decrease trend, as shown in Figure 4 (a), (b), (c) and (d).

\section{Experimental verification}

\subsection{Object and method}

Experimental verification is taken for MJF-30-6 fault simulation generator in the State Key Lab of New Energy and Electric Power System, P.R. China, as presented in Figure 5 (a) and Tab.1. During the experiment, MJF-30-6 fault 
simulation generator is paralleling operation. $\mathrm{P}=4.08 \mathrm{~kW}, \mathrm{Q}=0.83 \mathrm{kvar}, \mathrm{I}_{\mathrm{f}}=2.85 \mathrm{~A}, \mathrm{U}=400 \mathrm{~V}, \mathrm{I}=6.4 \mathrm{~A}$. In the experiment, the rated value of excitation current under each operation condition is 1A. The two short-circuit taps of C1 and $\mathrm{C} 2$ are selected for fault test. Taking into account the safety of the experiment, a slide-wire rheostat is connected in series between $\mathrm{C} 1$ and $\mathrm{C} 2$. (see Figure 5 (b)-(c)). The different short-circuit degrees are simulated by adjusting the resistance of the slide-wire rheostat.

The vertical vibration of generator stator core is measured by CD-21C type vibration speed sensor, and its sensitivity is $30 \mathrm{mV} / \mathrm{mm} / \mathrm{s}$. (see Figure 5 (d)). The output end of the vibration speed sensor is connected to the U60116 type acquisition instrument, and the sampling frequency is $5 \mathrm{KHz}$. The signal collected by the acquisition instrument is accordingly processed. In order to reduce the influence of faults on the transient process of generator, the excitation current is reduced at first and then the conductors are directly shorted, finally the excitation current is increased. The signal collected by the collector will be processed by experimental test system, as shown in Figure 5 (e).

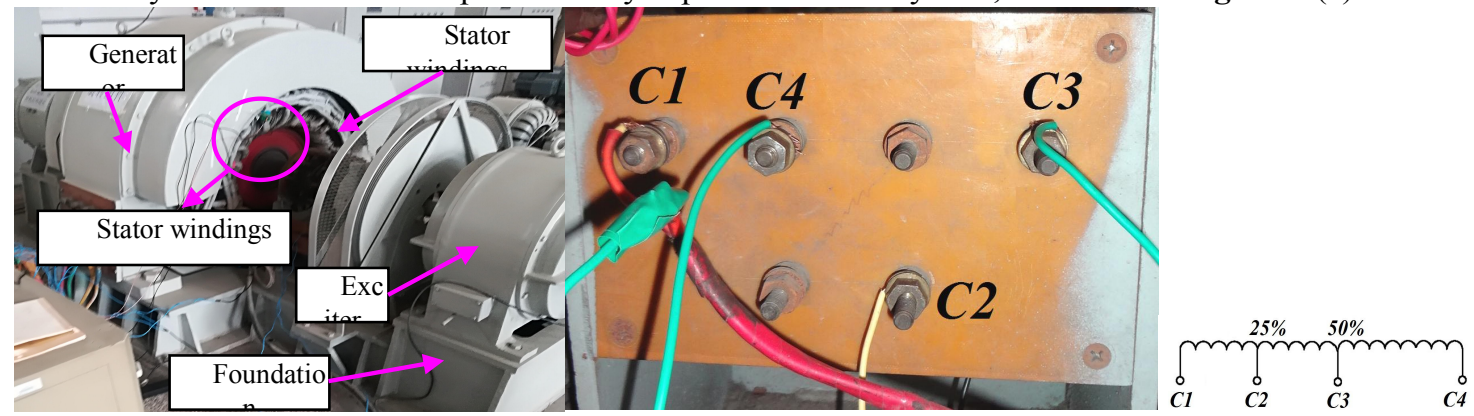

(a) MJF-30-6 fault simulation generator (b) Method to set rotor FWISC (c) Method to set rotor short-circuit taps

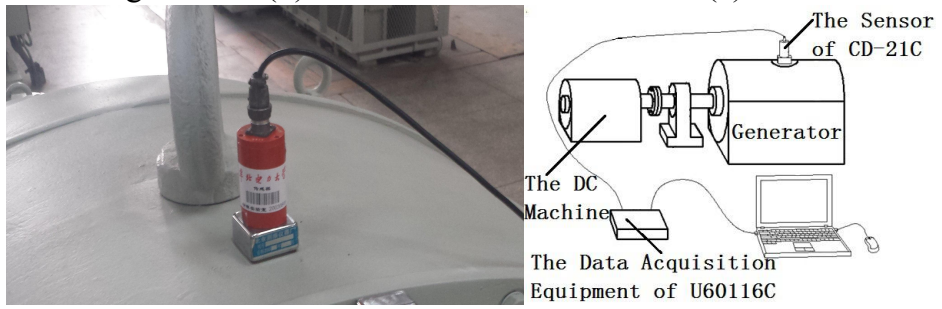

(d) Installation method of vibration velocity sensor (e) Experimental test system

Figure 5. MJF-30-6 type fault simulating generator and method to test the stator vibration.

\subsection{Results and discussion}

In order to study the variation rules of stator MPPUA, time domain waveforms of stator MPPUA as well as the spectra obtained from the experimental verification for normal condition and different short-circuit degrees are

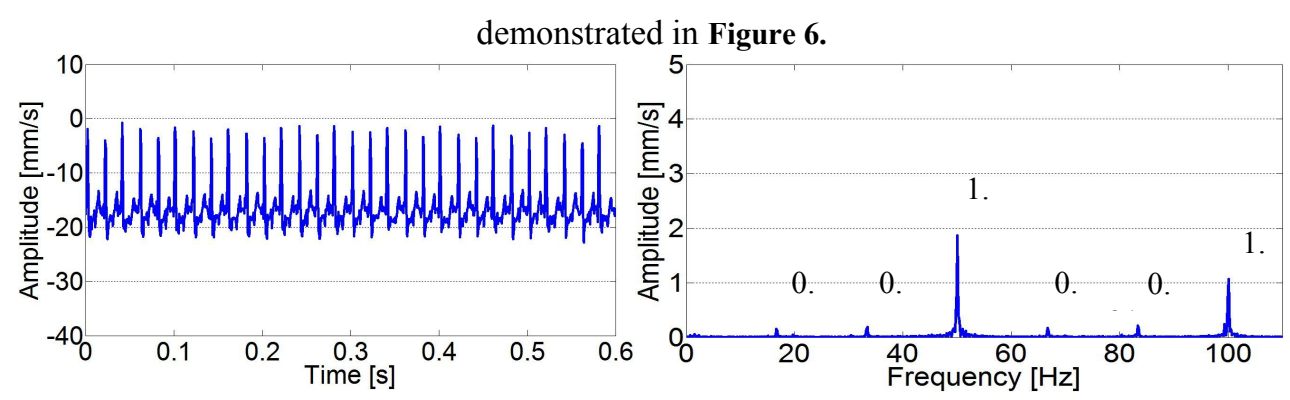

(a) Stator vibration waveforms and spectra under normal condition 

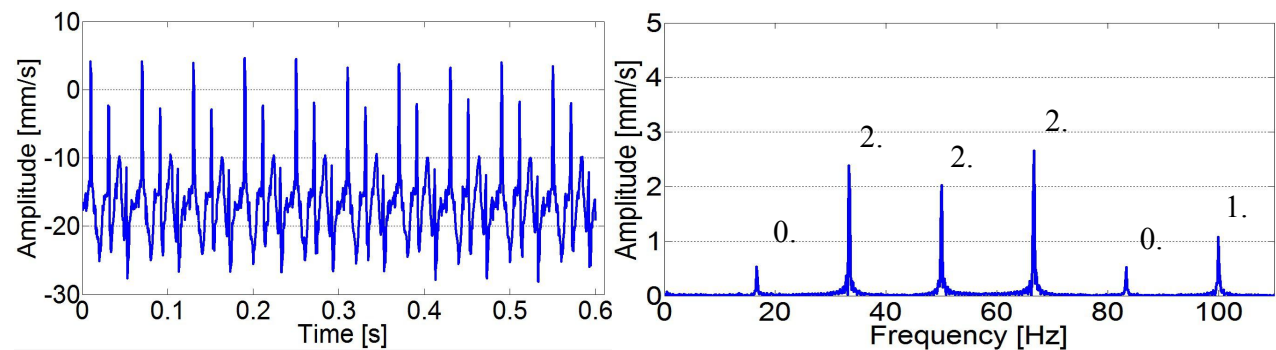

(b) Stator vibration waveforms and spectra under FWISC (shorted 2\%)
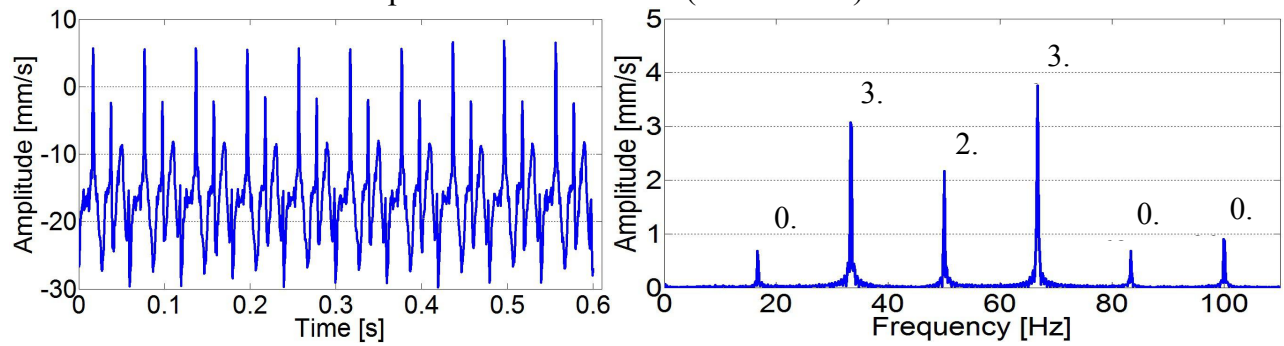

(c) Stator vibration waveforms and spectra under FWISC (shorted 5\%)

Figure 6. Stator vibration waveforms and spectra under different running conditions.

The experimental results are consistent with the results of numerical simulation. The main component of stator MPPUA is 6th-harmonic component under normal condition. The occurrence of FWISC will bring in 1st, 2nd, 3rd, 4th and 5th-harmonic components to MPPUA, as presented in Figure 6 (a) and (b). Meanwhile, with the increasing of the short-circuit degrees, the amplitudes of 1st, 2nd, 3rd, 4th and 5th-harmonic components will present an increasing trend. However, the amplitudes of 6th-harmonic component will present a decrease trend, as shown in Figure 6 (a), (b) and (c).

\section{Conclusion}

The variation rules of stator MPPUA characteristics under normal condition and different short-circuit degrees by the comparative study of 3D simulation and experiment. The results can be as follow:

(1) Normal condition, the main component of stator MPPUA is 6th-harmonic component.

(2) The occurrence of FWISC will bring in 1st, 2nd, 3rd, 4th and 5th-harmonic components to the stator MPPUA. In other words, the main harmonic components of MPPUA under FWISC are 1st, 2nd, 3rd, 4th, 5th and 6th-harmonic components. Specifically, with the increasing of the short circuit degrees, the amplitudes of 1st, 2nd, 3rd, 4th and 5th-harmonic components will present an increasing trend. However, the amplitudes of 6th-harmonic component will present a decrease trend.

Acknowledgement

This work is supported by National Natural Science Foundation of China (51777074), Natural Science Foundation of Hebei Province, China (E2015502013), and Chinese Fundamental Research Funds for the Central Universities (2018YQ03).

\section{References}

1. Kanjun $\mathrm{H} Z$, Yong Z. Detection of turbine generator field winding serious inter-turn short circuit based on the rotor vibration feature [C]. 2009 44th International Universities Power Engineering Conference (UPEC). IEEE 2009; pp.1-5.

2. Albanese R, Calvano F, G.Dal Mut F, et al. Coupled three dimensional numerical calculation of forces and stresses on the end windings of large turbo generators via integral formulation [J]. IEEE Transactions on Magnetics. 2012; 48(2): pp.875-878.

3. ALBRIGHT D R. Inter-turn short circuit detector for turbine generator rotor windings [J]. IEEE Transactions on Power and Apparatus Systems. 1971; 90(2): pp.478-483.

4. Dallas S E, Safacas A N, Kappatou J C. A study on the transient operation of a salient pole synchronous generator during an inter-turn stator fault with different number of short-circuited turns using F.E.M [C]. International 
Symposium on Power Electronics Power Electronics, Electrical Drives, Automation and Motion, IEEE. 2012; pp.1372-1377.

5. Yucai Wu, Yonggang Li, Shuting Wan, et al. Investigation of turbine generator rotor winding inter-turn short circuit fault based on harmonic detection [C]. International Conference on Electric Utility Deregulation and Restructuring and Power Technologies. IEEE 2008; pp.829-833.

6. Liangliang Hao, Junyong $\mathrm{Wu}$, Zhanfeng chen, et al. Mechanism of effects of inter-turn short circuits in field windings on large turbo-generator vibration [J]. Automation of Electric Power System. 2014; 38(4): pp.25-31.

7. Yuling He, Weiqi Deng, Bo Peng, et al. Stator vibration characteristic identification of turbo-generator among single and composite faults composed of static air-gap eccentricity and rotor inter-turn short circuit [J]. Shock and Vibration. 2016.10.1, 2016.

8. Shuting Wan, Heming Li, Yonggang Li. Analysis of generator vibration characteristic on rotor winding inter-turn short circuit fault [J]. Proceedings of the CSEE. 2005; 25(10): pp.122-126.

9. Yuling He, Mengqiang Ke, Falin Wang, et al. Effect of static eccentricity and stator inter-turn short circuit composite fault on rotor vibration characteristics of generator [J]. Transactions of the Canadian Society for Mechanical Engineering. 2015; 39(4): pp.767-781.

10. Yucai Wu, Yonggang Li, Hening Li, et al. Analysis of turbine generator rotor vibration characteristic under electromechanical compound faults [J]. High Voltage Engineering. 2010; 36(11): pp.2687-2692.

11. Mengqiang Ke. Analysis on magnetic pull characteristics of coupling faults composed by eccentricity and rotor inter-turn short circuit of generator [D]. Baoding, North China Electric Power University 2016. 